\title{
Fundamentos de las medidas europeas contra la pobreza y la exclusión social en la Unión Europea
}

\author{
Grounds of European measures against poverty and social \\ exclusion in the European Union
}
Fundamentos das medidas europeias contra a pobreza e a exclusão social na União Europeia

José Eduardo López Ahumada*

\begin{abstract}
RESUMEN
Este artículo realiza un análisis retrospectivo de las principales medidas de lucha contra la pobreza y la exclusión social en el ámbito de la Unión Europea. El estudio tiene presente el origen y los fundamentos de las medidas de contención de la precariedad en el trabajo en Europa, intentando destacar los importantes logros conseguidos en un momento de reforma y redefinición del sistema de protección social. La Unión Europea debe ser consciente de los importantes avances conseguidos, que requieren ser preservados en época de crisis económica y social. El trabajo analiza los fundamentos esenciales que orientaron el fomento de la solidaridad, la lucha contra la pobreza y la exclusión social en la Unión Europea.
\end{abstract}

\section{SUMMARY}

This article provides a retrospective analysis of the main measures to combat poverty and social exclusion in the European Union. The study considers the origin of efforts targeted at containing precariousness at work in Europe, trying to highlight the
Palabras clave:

relaciones

laborales, pobreza, exclusión social, políticas sociales.

Key words: labor relations, poverty, social exclusion, social policies.

* Doctor en Derecho por la Universidad de Alcalá. Académico correspondiente de la Real Academia de Jurisprudencia y Legislación de España. Director de la revista Estudios Latinoamericanos de Relaciones Laborales y Protección Social (ISSN: 2445-0472), publicada por Ediciones CINCA. Investigador Principal de la Línea estable de investigación en Relaciones Laborales y Protección Social del Instituto Universitario de Estudios Latinoamericanos de la Universidad de Alcalá (IELAT), Madrid, España. E-mail: eduardo. lopez@uah.es. 
crucial achievements at a time of reform and redefinition of the social protection system. The European Union must be aware of the critical advances achieved, which need to be preserved in economic and social crises. The work analyzes the essential foundations that have guided the promotion of solidarity, the fight against poverty and social exclusion in the European Union.

\section{RESUMO}

Este artigo realiza uma análise retrospectiva das principais mePalavras-chave: didas de luta contra a pobreza e a exclusão social no âmbito da relações laborais, União Europeia. O estudo considera a origem e os fundamentos das medidas de contenção da precariedade no trabalho na Europa, tentando destacar as importantes conquistas obtidas em pobreza, exclusão social, políticas sociais. um momento de reforma e redefinição do sistema de proteção social. A União Europeia deve ser consciente dos importantes avanços conseguidos, que requerem ser preservados em época de crise econômica e social. O trabalho analisa os fundamentos essenciais que orientaram a promoção da solidariedade e a luta contra a pobreza e a exclusão social na União Europeia. 


\section{Introducción}

La exclusión social y la pobreza son realidades que se proyectan en la sociedad y representan un gran problema causado por las desigualdades entre las personas. Estas desigualdades, cuando tienen una mayor repercusión, dan lugar a procesos sociales estructurales que pueden llegar a transformar profundamente los equilibrios sociales necesarios. Dicha situación ha sido una preocupación de la Unión Europea, que ha intentado corregir la situación. Se ha intentado mejorar el empleo, el fomento de la solidaridad, la lucha contra la pobreza y la exclusión, muy especialmente mediante el desarrollo de la igualdad de oportunidades y la libre circulación de personas. El presente trabajo intenta destacar los importantes avances conseguidos en la Unión Europea en materia de contención de la pobreza y limitación de la exclusión social. El objetivo del trabajo es analizar, de manera retrospectiva, los principales logros conseguidos en su momento, con la finalidad de subrayar su relevancia en la actualidad, en un contexto presidido por las reformas ante la crisis económica y social.

\section{La pobreza en las relaciones laborales en los mercados de trabajo de la Unión Europea: un problema estructural}

Desde sus propios orígenes, la Unión Europea ha venido defendiendo el objetivo de la cohesión social como cuestión vinculada al propio desarrollo del mercado interior. Ciertamente, desde el propio Tratado de Roma se han ido produciendo importantes progresos en la materia, lo que ha permitido una importante mejora de las condiciones de vida y bienestar de los ciudadanos. El fin es claramente la consecución de importantes espacios de inclusión, luchando contra la pobreza en sus distintas modalidades ${ }^{1}$. Ciertamente, la exclusión social y la pobreza son realidades que se proyectan en la sociedad, y representan un gran problema causado por las desigualdades entre las personas. Estas desigualdades, cuando tienen una mayor repercusión, dan lugar a proce-

1 En este sentido, debemos tener en cuenta la Comunicación de la Comisión al Parlamento Europeo, al Consejo, al Comité Económico y Social Europeo, y al Comité de las Regiones titulada "La Plataforma Europea contra la Pobreza y la Exclusión Social. Un marco europeo para la cohesión social y territorial", Plataforma contra la Pobreza. Una iniciativa de la Unión Europea, Luxemburgo, 2011. 
sos sociales estructurales, que pueden llegar a transformar profundamente los equilibrios sociales necesarios.

La actual crisis económica y social que afecta a los países europeos, está planteando una profunda revisión del modelo de protección social. En estos momentos es importante tener en cuenta las grandes conquistas alcanzadas en su momento en la materia. Conviene, pues, repasar los hitos más relevantes desde el punto de vista de la protección contra la pobreza y la exclusión social. No hace muchos años, concretamente en noviembre de 2017, las instituciones de la Unión europea manifestaron su preocupación por la defensa del pilar europeo de los derechos sociales, en una proclamación conjunta. Dentro de este pilar social se encuentra especialmente la protección contra la pobreza y la inclusión social y, en concreto, el desarrollo de las políticas sociales y de protección del empleo.

Actualmente el Parlamento Europeo ha ensalzado la necesidad de reforzar la acción de la Unión Europea orientada a la mejora de las condiciones de vida, reduciendo las manifestaciones de pobreza. Sin duda, el gran referente fue la resolución de 8 de octubre de 2020, sobre políticas en materia social y de empleo en la zona euro. Se trata de una resolución que se preocupa especialmente por los efectos devastadores que ha tenido la crisis del covid-19. Concretamente, se demanda a la Comisión Europea que desarrolle una acción política que sustituya a la estrategia europea 2020, con el objetivo de erradicar la pobreza. Dicha estrategia se enmarca igualmente en la necesidad de aplicar la Agenda 2030 de Naciones Unidas para el desarrollo sostenible, en consonancia con las acciones propias de los Estados miembros. La Agenda 2030 se presenta actualmente como el marco general para el desarrollo sostenible, teniendo como objetivo la lucha contra la pobreza y la consecución de mayores cuotas de inclusión social. En el ámbito europeo, se trata de un objetivo esencial, que se orienta a promover igualmente la convergencia entre los países de la Unión Europea.

La exclusión social supone aislar total o parcialmente a determinados individuos o grupos de la participación plena en la sociedad (Arroyo Bovea, 2016). Evidentemente, la noción de "exclusión social" guarda una relación indisoluble con la pobreza. La exclusión social no es más que una causa de la propia pobreza. De este modo, el au- 
mento de la pobreza genera irremediablemente exclusión social y ahonda en los desequilibrios sociales, lo que impide que una persona pueda situarse en el estándar mínimo de vida. Efectivamente, los conceptos de "pobreza" y "exclusión" tienen su propio sentido evolutivo, y dependen sobremanera del contexto social y económico (Rojas Mullor, 2011; Room, 1995). Con todo, este estándar de vida se presenta, pues, como el umbral necesario para la consideración del desarrollo de una vida digna. En este sentido, conviene indicar que este concepto de pobreza ha ido evolucionando con el paso del tiempo, pasando de tener una noción estrictamente económica, para evolucionar y alcanzar una concepción de naturaleza social. Sin duda, ello nos conduce a metas mucho más ambiciosas, que sobrepasan las cuestiones económicas o materiales, con el fin de intentar satisfacer necesidades sociales en sentido amplio. Ciertamente, esta situación ha sido una preocupación de la Unión Europea, que ha intentado corregir la situación. Se ha intentado mejorar el empleo, el fomento de la solidaridad, la lucha contra la pobreza y la exclusión, muy especialmente mediante el desarrollo de la igualdad de oportunidad y la libre circulación de personas ${ }^{2}$.

Con todo, la noción de "pobreza" debe complementarse con la idea de "exclusión social", que permite avanzar en un concepto más amplio de "protección" ante las desigualdades entre los ciudadanos. Efectivamente, este proceso ha supuesto incluso una sustitución de la noción de la "pobreza", cobrando mayor relieve y sentido la referencia a la exclusión social. Dicho matiz se ha incorporado igualmente, como veremos, en la propia acción de la Unión Europea. Ello es importante, porque permite evaluar el acceso y disfrute a los derechos sociales básicos y el grado de promoción de la igualdad y no discriminación ${ }^{3}$. Con todo, la evaluación de la exclusión social depende de su propia intensidad,

2 Ciertamente, este objetivo forma parte de una acción transversal de la Unión Europea que sobrepasa el estricto ámbito laboral. Desde esta perspectiva, la Unión Europea ha intentado "mejorar la situación del empleo, el desarrollo de recursos humanos, fomentar la solidaridad y la integración, la lucha contra la pobreza y la exclusión, la igualdad de oportunidades entre hombres y mujeres, el reforzamiento del diálogo social y el mercado único, y la libre circulación de las personas" (Quesada Díez, 1998).

3 Con todo, esta mejora terminológica tiene igualmente importantes obstáculos. Con carácter general, se ha indicado que unos de los principales problemas es la ausencia de acuerdo sobre los datos estadísticos que puedan mostrar de manera adecuada la extensión y evolución del concepto de exclusión social. 
ya que caben distintos grados de afectación, lo que permite analizar si una sociedad es excluyente según los colectivos afectados ${ }^{4}$.

\section{El impacto de la exclusión social en la Unión Europea}

Con carácter general, conviene destacar que la situación europea es ciertamente heterogénea. En este sentido, se apunta a la Europa del Este $^{5}$ y a la Europa Mediterránea como las regiones que tienen un mayor impacto de riesgo de pobreza y exclusión social ${ }^{6}$. Particularmente, la Europa Central tiene unos índices de exclusión mucho más bajos (Lois, 2013). En gran medida la explicación se encuentra en las diferencias en las políticas sociales promovidas por los distintos países, así como por los propios niveles de protección social existentes que protegen a la población ${ }^{7}$.

Actualmente, los índices de población en riesgo de pobreza han aumentado considerablemente, debido especialmente a la proyección de la crisis del coronavirus. Precisamente, debido a la crisis y a la inseguridad de sus efectos, no tenemos datos fiables sobre el duro impacto sufrido en materia de pobreza. No obstante, si nos atenemos a los datos de principios de 2020, previos a la crisis, observamos que el índice de población en situación de riesgo de pobreza se encontraba en torno al $18 \%^{8}$. En 2017, en el conjunto de la Unión Europea había un $17 \%$

4 El autor destaca especialmente dos grados de exclusión social, en atención a la gravedad de la situación de la persona. Una primera manifestación más intensa se refiere a la pobreza, por la situación de las personas que están en circunstancias de pobreza extrema. Seguidamente se detectan los marginados sociales, que pueden llegar a situarse en exclusión de pobreza y cuya situación puede atenderse y corregirse. En este colectivo nos encontramos a los desempleados, ancianos, discapacitados, minorías étnicas o inmigrantes (Gil Villa, 2002).

5 En el caso de la Europa del Este, los países que se anexionaron más tarde a la Unión Europea reflejan los valores más altos de riesgo a la pobreza. Ello se debe a que se trata de una zona más pobre y menos desarrollada. Ciertamente, en esta área se deben realizar aún grandes esfuerzos de integración en materia social, para poder equipararse al resto de países de la Unión.

6 En el seno de la Unión Europea existen países que tienen un mayor riesgo de exclusión social. Asimismo, podemos indicar que, dentro de un mismo país, hay regiones más vulnerables que otras debido a sus características. Es decir, existen regiones que tienen una mayor propensión a que la población caiga en riesgo de exclusión social.

7 Tradicionalmente se ha apuntado a países como Grecia y España como claros ejemplos de alto riesgos de exclusión social. Esta situación incluso se ha potenciado durante el largo período de crisis económica.

8 Vid. Europe 2020. A European strategy for smart, sustainable and inclusive growth (2020). 
de población en riesgo de pobreza, situación que se producía incluso después de haber recibido algún tipo de protección social ${ }^{9}$. Dicha situación, persistente en el tiempo, se presenta realmente como un problema social estructural que necesita nuevas medidas de protección.

Especialmente relevante es el hecho de que el número de personas pobres con empleo ha aumentado considerablemente en Europa desde el inicio de la crisis, situación que afecta a más de dos millones y medio de personas en la Eurozona (Lacuesta y Brindusa, 2020). Concretamente, entre 2005 y 2012 las personas no pensionistas en riesgos de pobreza aumentaron especialmente, llegando a alcanzar una cuota del 5,9\%. Igualmente, esta situación se ha ido manteniendo e incluso aumentando con el paso de los años, situándose a principios de 2020 en torno al $7 \%{ }^{10}$. Asimismo, las personas que se encuentran en situación de riesgo de pobreza, después de la atención social de los Estados, han aumentado igualmente. En el caso particular de España, se considera que doce millones y medio de personas viven en riesgo de pobreza y exclusión social, según datos del Instituto Nacional de Estadística ${ }^{11}$.

Evidentemente, la crisis económica ha incidido intensamente en las acciones de lucha orientadas a la reducción de la exclusión social y la pobreza. Efectivamente, la pobreza ha aumentado y, ante esta situación, se debería de prestar más atención a las medidas de lucha contra la pobreza y la exclusión social desde la Unión Europea. Los ciclos de recesión económica han afectado especialmente a la dimensión social del proyecto europeo. La crisis de los años setenta impidió conseguir el objetivo del modelo social europeo, que se entendía era capaz de acabar con la pobreza en Europa. En ese momento se atribuyó el aumento

9 Incluso antes de 2017, Eurostat llegó a la conclusión de que aproximadamente el $13 \%$ de la población de la Unión Europea encontraba graves obstáculos inclusión social. El 4\% se veía afectada intensamente y el 9\% tenía un mayor grado de incursión en estas situaciones exclusivas. Vid. Statistics in Focus (1995).

10 Vid. Europe 2020. A European strategy for smart, sustainable and inclusive growth (2020).

11 En España, 12 millones y medio de personas se encuentran en riesgo de pobreza o exclusión social, lo que representa el $26,1 \%$ de la población. Vid. Encuesta de Condiciones de Vida del año 2020. Con carácter general, a principios del año 2020 se percibía una cierta mejoría en la tasa general de pobreza, pero no cabe duda de que con la crisis del coronavirus las cuotas de pobreza han aumentado considerablemente y hay muchos colectivos que no perciben ese margen de mejora. Vid. El Estado de la Pobreza. España 2020 X Informe anual sobre el riesgo de pobreza y exclusión (2020). 
de la pobreza a las elevadas tasas de desempleo asociadas a la crisis del momento. Entonces, la Comunidad Económica Europea desarrolló unos programas de lucha contra la pobreza como consecuencia del impacto social que la crisis industrial de 1973 estaba teniendo en las condiciones de vida de millones de trabajadores sin empleo.

La situación es, pues, estructural, y la pobreza en Europa no remite, ni siquiera en Europa occidental. Incluso esta situación se potencia en los ciclos de crisis económica, que atraen nuevos problemas a los mercados de trabajos nacionales. Actualmente, debido a la crisis económica, se han producido profundos cambios en las estructuras económicas, políticas y sociales de los países. Ante esta situación, la Unión Europea debe buscar un nuevo modelo para mantener el núcleo social de protección, sin que ello suponga una pérdida de competitividad en el ámbito internacional. La Unión Europea está encontrando nuevos retos en un escenario mucho más complejo, presidido por la globalización económica y el dumping social. Esta circunstancia se une a otros factores, como son el envejecimiento de la población y su incidencia en la financiación de los sistemas públicos de protección social ${ }^{12}$.

\section{La estrecha vinculación de la lucha contra la pobreza en el ámbito laboral y social}

La lucha contra la pobreza supone combatir la exclusión social y la discriminación en la sociedad, y muy especialmente en ámbito laboral. Ello supone que los Estados deben combatir la pobreza integrando y cohesionando a la sociedad, permitiendo que los ciudadanos tengan las mismas oportunidades y recursos. Se trata de un objetivo que está presente en el Tratado de Funcionamiento de la Unión Europea (arts. 19, 145 a 150, 151 a 161 TFUE). El propio art. 19 del TFUE permite que la propia Unión Europea tome medidas orientadas a evitar la discriminación, ofreciendo especial protección a los colectivos potencialmente afectados. Precisamente, el art. 19.1 TFUE atribuye al Parlamento Europeo la facultad de desarrollar la legislación sobre no discriminación.

12 Precisamente, ante este nuevo escenario la Comisión ha propuesto cinco ambiciosos objetivos a seguir en la Unión Europea en un período de una década. La Comisión hace corresponsables a los Estados miembros de su logro. Dichos objetivos transversales son el empleo, la investigación y la innovación, el cambio climático y la energía, la educación y la lucha contra la pobreza. 
En este sentido, es preciso destacar la importancia del Tratado de Ámsterdam, de 1997, que declaraba la erradicación de la exclusión social como objetivo propio de la política social comunitaria (Fernández García, 2012; Gil, 2009; Quesada, 1998). Asimismo, el art. 160 TFUE creó el Comité de Protección Social, configurado como órgano competente para impulsar la cooperación entre los Estados Miembros y la Comisión. En el Tratado de Ámsterdam de 1997 se incluyó un artículo específico sobre la lucha contra la exclusión social, estableciendo las bases para una política de inclusión social europea. Precisamente, en febrero de 2000, la Comisión europea anunció una nueva serie de objetivos orientados a la creación de la Europa Social, desarrollando un nuevo marco jurídico para las políticas sociales y económicas. Se adoptó un plan de acción de cinco años para cubrir el periodo 20002005, promocionando la interrelación entre el dinamismo económico, el pleno empleo y la justicia social entre Estados Miembros. Desde esta perspectiva, la combinación del crecimiento económico, el empleo y la cohesión social se consideraban como elementos claves para el avance en el propio proceso de integración europea ${ }^{13}$.

Posteriormente, este objetivo fue incluso intensificado con la Estrategia de Lisboa. Ello supuso un paso más, ofreciendo nuevos mecanismos de supervisión y coordinación. En concreto, se prestó especial atención al análisis de la pobreza y su medición, considerando nuevos indicadores. La Unión Europea venía, pues, a enunciar nuevas directrices para los Estados miembros, fomentando los planes nacionales contra la pobreza. En 2005 la Comisión Europea propuso el "MAC social", que vino a impulsar las políticas de protección social e inclusión. El objetivo era la cohesión social y la igualdad de oportunidades, especialmente mediante sistemas eficaces de protección social ${ }^{14}$.

13 Sin duda, el objetivo de la integración regional, tanto económica como social, ha sido destacado tradicionalmente en los principales instrumentos comunitarios. Véase, Informe final sobre la aplicación del programa comunitario para la integración económica y social De los grupos menos favorecidos "POBREZA 3" (1989-1994). Bruselas, 27.03.1995 COM(95) 94 final.

14 Efectivamente, todo ello requería de una estrategia global integrada y orientada a la inclusión activa de las personas excluidas del mercado laboral, primando el desarrollo de mercados de trabajo inclusivos y el acceso a unos servicios de calidad (Recomendación 92/441/CE del Consejo). 


\section{El desarrollo de la promoción de la cohesión social y la erradicación de la pobreza en las relaciones laborales}

La normativa europea de desarrollo del tratamiento de la pobreza y la exclusión social tiene su fundamento en el art. 13 del Tratado Constitutivo de la Comunidad Europea (art. 19 TFUE). Como sabemos, dicho precepto permitía al Consejo adoptar medidas para combatir la discriminación por distintos motivos, entre ellos, por origen racial o étnico, la religión o las creencias, la edad, la discapacidad y la orientación sexual. Su redacción fue modificada por el Tratado de Niza, que contempla la posibilidad de prever medidas de incentivo de las políticas antidiscriminatorias. Con base en estas normas, se desarrolló un importante bloque de directivas. En concreto, podemos destacar la proyección de la Directiva sobre la igualdad de trato de las personas independientemente de su origen racial (2000/43/CE), la Directiva sobre la igualdad de trato en el empleo y la ocupación (2000/78/CE), y la Directiva sobre la igualdad de trato (2006/54/CE). Precisamente, esta última Directiva venía a refundir varias directivas anteriores relativas a la igualdad de oportunidades entre hombres y mujeres ${ }^{15}$.

Ciertamente, se trata de un tema centrado especialmente desde el punto de vista de las políticas sociales comunitarias. La exclusión social tiene un importante asiento jurídico en la legislación europea antidiscriminación y forma parte de la propia política social europea. La cuestión social ha sido un pilar fundamental de la Unión Europea. Ya durante la propia Comunidad Europea se vino a definir la noción de "pobreza" como elemento clave para entender el significado de la exclusión social. Con la aplicación de los primeros planes de lucha contra la pobreza y la exclusión social, en 1975 la Comunidad Europea

15 Igualmente, podemos citar una serie de propuestas de Directivas presentadas por la Comisión orientadas a promover la igualdad, que necesitaban el correspondiente acuerdo del Consejo. Entre ellas podemos citar: Directiva sobre el equilibrio de género en los consejos de administración de las empresas (2012) y Directiva por la que se aplica el principio de igualdad de trato entre las personas fuera del contexto laboral (2008). 
vino a definir el significado de "pobreza" ${ }^{16}$, aludiendo a la situación en la que "individuos o familias tienen recursos tan reducidos que los excluyen del estilo de vida considerado mínimamente aceptable para el Estado Miembro en el que habitan"17. En este mismo sentido, en 1985 el Consejo avanzó enunciando una definición de personas pobres ${ }^{18}$, en referencia a "los individuos, las familias y los grupos de personas cuyos recursos (materiales, culturales y sociales) son tan escasos que no tienen acceso a las condiciones de vida mínimas aceptables en el Estado Miembro en que viven" (Arriola, 2014).

La exclusión social y la pobreza son dos problemas interrelacionados, cuyos efectos se pretenden reducir mediante la toma de medidas impulsadas por la Estrategia Europea 2020. Ciertamente, las políticas sociales europeas tratan de dar mayor coherencia a la estrategia global social, con el objetivo de luchar contra la pobreza. En este sentido, el Consejo ha venido elaborando una serie de objetivos en la lucha contra la pobreza y la exclusión social, insistiendo en que la Unión Europea tiene, entre sus principales fines, la lucha contra ellas. Ello se presenta institucionalmente como "uno de los elementos centrales de la modernización del modelo social europeo" ${ }^{19}$.

Ciertamente, las políticas de inclusión social, bien orientadas y con el decidido apoyo institucional europeo y nacional, son una herramienta clave en la consecución de la inversión social ${ }^{20}$. Uno de los problemas más relevantes en esta materia es la propia indefinición de las

16 Ciertamente, las primeras alusiones a la acción contra la pobreza en la Comunidad se remontan a la Resolución del Consejo, de 21 de enero 1974. En ese momento, se aprobó un programa de acción social para el periodo 1974-1976. Asimismo, podemos destacar de las decisiones del Consejo, las medidas específicas orientadas al programa de lucha contra la pobreza, de 22 de julio de 1975 y 12 de diciembre 1977, formuladas por la Comisión Europea en 1981. El primer programa europeo de lucha contra la pobreza se desarrolló entre 1975 y 1980, y ello a pesar de la indefinición institucional de la noción de pobreza.

17 Vid. Decisión del Consejo Europeo de 22 de julio de 1975, relativa al programa piloto de estudio y lucha contra la pobreza (1975).

18 Decisión del Consejo de 19 de diciembre de 1984, relativa a una acción comunitaria específica de lucha contra la pobreza (1984).

19 Esta declaración se pronunció expresamente en el Consejo Europeo 2001. La Comisión prestó especial atención a la dimensión social de la gobernanza de la cohesión social, y se centró en el desempleo juvenil, la renta disponible en los hogares, la tasa de riesgos de pobreza y la desigualdad de renta. Vid. Hacia la inversión social para el crecimiento y la cohesión (2013).

20 Vid. Investing in a social Europe. Report on the second annual conference of the European Platform against Poverty and Social Exclusion (2012). 
políticas sociales comunitarias. Dicha afirmación nos sitúa ante una verdadera crisis del modelo, que habría que cuestionar. Ciertamente, la pobreza y la exclusión social adoptan formas complejas en la realidad y deben ser atendidas en función de diversas políticas sociales, que deberían enmarcarse en una estrategia global consensuada institucionalmente. La política de empleo y la protección social tienen un papel esencial, y permiten corregir las principales manifestaciones de discriminación en la sociedad ${ }^{21}$.

En su momento, la Cumbre de Niza aseguró un fundamento político que permitió consolidar la Agenda Social Europea. En concreto, se vino a reforzar el programa de modernización del modelo social europeo, prestando especial atención a la estrecha relación entre el rendimiento económico y el necesario progreso social. Posteriormente, la Cumbre de Lisboa supuso un importante avance en la materia. Se venía a reforzar el modelo social europeo, en el que los aspectos de progreso económico y social no están excluidos, sino que deben avanzar de forma progresiva y paralela ${ }^{22}$. Precisamente, uno de los objetivos de la Cumbre de Lisboa fue examinar las políticas existentes contra la pobreza y la exclusión social, con el fin de orientar a los Estados Miembros y así permitir la consecución de mejores oportunidades de empleo, como medida de contención de la pobreza y la exclusión social.

Desde esta perspectiva, en la Cumbre de Lisboa se venía a reafirmar igualmente la necesidad de orientar una estrategia renovada de lucha contra la pobreza y la exclusión social. Una estrategia formulada de forma transversal, que vendría a orientar el conjunto de políticas sociales de la Unión Europea y de los Estados miembros. Este nuevo enfoque permitía una auténtica coordinación institucional de un problema ciertamente común, que ponía en cuestión el propio

21 Con todo, no solamente se debe atender la vertiente laboral y de protección social. Es preciso tener en cuenta otros factores, como la vivienda, la educación, la salud, la información, la movilidad, el tiempo libre, la cultura, la seguridad y la justicia. Ello implica la necesidad de integrar las diferentes políticas nacionales y europeas, orientándolas al objetivo de luchar contra la pobreza y la exclusión social. Esta naturaleza transversal (mainstreaming) fue puesta de manifiesto en el Consejo Europeo 2001.

22 En concreto, una de las declaraciones de la Cumbre se refería a la necesidad de avanzar hacia una "Europa [que] debería convertirse en la sociedad basada en el conocimiento más dinámica y competitiva del mundo, capaz de lograr un crecimiento económico sostenible, con mejores empleos y mayor cohesión social". 
modelo social europeo ${ }^{23}$. En este sentido, ello supuso estimular los Planes Nacionales de Acción para combatir la pobreza y la exclusión social, que ya fueron aplicados durante la década anterior. Asimismo, suponía el establecimiento de un Programa de Acción Europeo, que venía a fomentar la cooperación institucional y el intercambio de información sobre las mejores políticas aplicadas en el seno de la Unión Europea.

Sin duda, se trata de una base institucional que permite el desarrollo de la Plataforma Europea contra la Pobreza y la Exclusión Social ${ }^{24}$. Estas acciones institucionales representan la propia contribución de la Unión Europea para afrontar los retos que enuncia la Estrategia Europea. En concreto, se centra en la necesidad de atender a una gran diversidad de factores que generan pobreza y exclusión social en Europa (Podadera, Romero, García y Lobato, 2020). Sin duda, el más importante es el desempleo, que permite hablar de un índice de riesgo de pobreza del $44 \%$ de los desempleados (Herrara Ballesteros, 2020). Y ello, claro está, sin olvidar la alta cuota que representa actualmente el trabajo precario. Se viene diciendo que el conjunto de trabajadores ocupados pobres está en torno al $10 \%$, circunstancia que se debe esencialmente a los bajos niveles de ingresos de la renta derivada del trabajo.

\section{Principales manifestaciones de la pobreza en el acceso al empleo, en el trabajo y en el desempleo}

Los factores desencadenantes de la exclusión social derivan principalmente de los cambios estructurales a los que están sometidas las economías y las sociedades. Efectivamente, el empleo es un factor esencial que determina la presencia de la pobreza en las sociedades actuales. El nivel de ingresos y, por tanto, la vulnerabilidad a incurrir en situaciones de riesgo de pobreza viene determinado por el hecho de contar con un empleo y, asimismo, por las condiciones de trabajo que

23 Se venía, pues, a insistir en que era necesario un nuevo entendimiento. En concreto, "una mejor coordinación de las políticas significa que tiene que evaluarse cuidadosamente el impacto social de las iniciativas de actuación, y que las consecuencias sociales potencialmente adversas han de minimizarse con medidas orientadas a la equidad y centradas en la pobreza". Cumbre de Lisboa de 2010.

24 Vid. La Plataforma Europea contra la Pobreza y la Exclusión Social: Un marco europeo para la cohesión social y territorial (2010). 
determinan su calidad. En Europa se han venido produciendo grandes cambios estructurales que han repercutido en el mercado laboral y ello se ha manifestado directamente en unas nuevas modalidades de pobreza. Se ha producido un aumento de empleos con salarios bajos, que cuentan con importantes manifestaciones de precariedad laboral. Ello ha conformado un nuevo tipo de trabajador pobre. Como se puede observar, el empleo condiciona ciertamente las propias tendencias de exclusión social.

Evidentemente, el empleo permite una fuente básica de ingresos y la ausencia de éste supone la situación de la persona en las situaciones de pobreza. Asimismo, la presencia del empleo viene a proteger adicionalmente a las personas, mediante el acceso a derechos como un salario mínimo o la protección social ${ }^{25}$. De este modo, "inserción en el mercado de trabajo" es sinónimo de "inserción social". La generación del empleo sumergido o no declarado priva a las personas de una protección digna y, a su vez, cercena sus propias posibilidades y oportunidades de integración social. Estos problemas se han acentuado exponencialmente en los países europeos, debido a los efectos derivados de la crisis económica y financiera que han desembocado en una crisis del empleo. Los grandes problemas siguen siendo la persistencia del desempleo, unida a las dificultades de inserción laboral, lo cual se refleja en la preocupación de las instituciones europeas de fomentar las dinámicas de integración social.

Desde esta perspectiva, no cabe duda de que la mejor manera de luchar contra la exclusión social es el empleo. El trabajo es la mejor protección contra la exclusión social, siempre que se desarrolle en condiciones de calidad. Precisamente, como veremos, este es unos los principales objetivos que la Unión Europea ha previsto en la Estrategia Europea para el empleo, que pretende contribuir a la lucha contra la exclusión social. Ciertamente, el crecimiento económico y la cohesión social deben estar estrechamente relacionados y, por tanto, son variables que bien conjugadas tienden a reforzarse mutuamente. Por tanto, en la medida en que la economía europea sea más potente, su

25 Ciertamente, esta forma de protección fomenta el acceso de las personas a derechos, recursos, bienes y servicios, y ello es consecuencia de la obtención de los recursos necesarios para vivir en condiciones de dignidad humana. Se trata de una situación de garantía, que permite superar los obstáculos de integración en la sociedad. 
sociedad debería estar más cohesionada socialmente, siendo ese crecimiento y desarrollo un límite a la exclusión social. El crecimiento del empleo y de los salarios son factores esenciales para reducir los niveles de riesgo de pobreza. Por tanto, en el modelo social europeo el sistema está llamado a asegurar el acceso a un empleo que permita la obtención de ingresos mínimos vitales, debiéndose asimismo fomentar la capacidad de inserción profesional ${ }^{26}$.

Asimismo, debemos prestar especial atención al tema del mantenimiento y mejora del poder adquisitivo de los trabajadores. La reducción del margen de pobreza está vinculada al nivel de renta de los trabajadores. Los incrementos salariales permiten revertir la situación de deterioro y precariedad laboral experimentada en el último ciclo de recesión económica. La evolución de los costes salariales se ha traducido en una lenta pero progresiva devaluación de los salarios. En Europa, los países del área mediterránea han sufrido muy especialmente este proceso, pero otros países tampoco son ajenos a la tendencia. Incluso Alemania o Suecia han experimentado un proceso de rebaja salarial que ha dado lugar a un aumento del porcentaje de población en riesgo de pobreza. En este sentido, la situación ha promovido, en el debate institucional, la cuestión de la renta mínima de inserción. El Parlamento Europeo, en su Resolución de 20 de octubre de 2010, abordó el tema del papel de la renta mínima en la lucha contra la pobreza, y la promoción de una sociedad integradora en Europa. Concretamente, el Parlamento respaldó la posibilidad de promover una renta mínima equivalente al $60 \%$ de la renta media del Estado Miembro en cuestión, así como la necesidad de prever un salario mínimo digno, que superase los umbrales de pobreza.

26 Estos ambiciosos objetivos presuponen la presencia de una política multidisciplinar y transversal desde el punto de vista del enfoque europeo de la exclusión social. El empleo debe fomentarse a través de las denominadas "políticas activas de empleo", sin descuidar otros factores relacionados con las posibilidades de empleabilidad en el mercado de trabajo. En este sentido, conviene destacar la necesidad de desarrollar la capacidad de inserción profesional, en particular gracias a la adquisición de competencias y a la formación permanente. En 2008, la Comisión elaboró una Recomendación para que los Estados de la Unión adoptasen políticas activas orientadas a la inclusión de los excluidos del mercado laboral. Vid. Recomendación de la Comisión Europea sobre inclusión activa de las personas excluidas del mercado de trabajo (2008). En concreto, se venía a recomendar el desarrollo de una estrategia global integrada entre el nivel local, regional, nacional y comunitario. 
Efectivamente, los sistemas nacionales de protección social tienen una función esencial, tanto en el nivel contributivo como asistencial. La protección social viene a garantizar los recursos suficientes en caso de necesidad. Los instrumentos de política de protección social definen al propio Estado social, el cual necesita de modernos sistemas públicos que permitan favorecer el acceso al empleo y asegurar las oportunas transiciones en el mercado de trabajo, sin olvidar el papel clave que tienen el acceso a las pensiones de jubilación y a la asistencia sanitaria como protección básica en la lucha contra la exclusión social. En Europa, el sistema se ha basado tradicionalmente en la garantía de un fuerte sistema de protección social como mecanismo de lucha contra la pobreza. Según las estadísticas, en los últimos diez años, en torno a un 10\% de la población europea necesitaba de las transferencias sociales de los sistemas de Seguridad Social para poder salir de las situaciones de riesgo de la pobreza. Y, por otro lado, un gran segmento de la población, que se estima alcanza los noventa millones de personas, depende del acceso a las pensiones para evitar el riesgo de la pobreza ${ }^{27}$. Sin duda, se trata de datos que, actualmente, se encuentran superados por la realidad del momento (se estima en $20 \%$ la cuota de población que necesita una asistencia por parte de la acción protectora de la Seguridad Social) ${ }^{28}$.

De igual modo, debemos destacar la especial proyección de la pobreza en los grupos especiales de riesgo. La atención debe ir dirigida a estos colectivos, aumentado su participación en el mercado de trabajo y mejorando también su integración por otras vías, como la formación. Ciertamente, el objetivo es la promoción de un equilibrio entre el mercado de trabajo, el acceso a servicios y la posibilidad de acceder a ingresos suficientes, como fórmulas de inclusión activa en la socie$\operatorname{dad}^{29}$. Es necesario, pues, abordar las necesidades de los grupos más

27 Vid. Informe sobre la ejecución, los resultados y la evaluación general del Año Europeo de la Lucha contra la Pobreza y la Exclusión Social (2012). SIN REFERENCIAS

28 Vid. Estrategia nacional de prevención y lucha contra la pobreza y la exclusión social 2019-2023 (2020). S

29 En el ámbito europeo, se ha priorizado el fomento de la participación en el empleo y del acceso a los recursos, derechos, bienes y servicios. La estrategia europea para el empleo y, en particular, la aplicación de las líneas directrices, implican la necesidad de favorecer el acceso a un empleo duradero y de calidad para todas las mujeres y todos los hombres en situación de trabajar. Ello se orienta especialmente a las personas que pertenezcan a los grupos de población más vulnerables, a cuyos efectos se priorizan planes de acompañamiento hacia el empleo, conjugados con políticas de formación. 
vulnerables, situación que afecta, con carácter general, a un conjunto amplio de situaciones. Entre ellas destacamos a las personas sin hogar, las con discapacidad, las personas mayores, las personas en situación de dependencia, la población inmigrante, las víctimas de violencia de género - especialmente mujeres y menores-, la población gitana, las víctimas de discriminación, las personas con adicción y las personas reclusas o exreclusas ${ }^{30}$.

Estos colectivos tienen mayores tasas de riesgo de pobreza y exclusión. Cada uno de ellos tiene sus problemas especiales y necesitan medidas concretas de actuación. Entre ellos podemos hacer mención de algunos colectivos que comúnmente tienen más relevancia social. La progresiva incorporación de las mujeres en el mercado de trabajo ${ }^{31}$, junto con la salida más temprana de la vida laboral y tardía incorporación de los jóvenes ${ }^{32}$, han creado nuevas situaciones de inseguridad y exclusión. Ello se ve acentuado por la crisis económica y por la propia naturaleza del empleo, generando nuevas situaciones de precariedad. Por otro lado, la inmigración es un proceso de especial relevancia en Europa, ya que los Estados de la Unión son un importante foco de recepción de inmigrantes, así como de ciudadanos de otros Estados miembros, más alejados de la real integración económica y social. Dichas personas buscan nuevas oportunidades en la Unión Europea, en virtud de la libre circulación de personas.

Las personas inmigrantes son especialmente sensibles al riesgo de exclusión social, debido a las diferencias culturales con la sociedad de acogida. Esta situación se potencia con las dificultades de inserción derivadas de la crisis económica. Asimismo, estas circunstancias se agravan debido a la falta de cualificación laboral, que les sitúa ante un

30 Vid. Recomendación de la Comisión, de 3 de octubre de 2008, sobre la inclusión activa de las personas excluidas del mercado laboral, C (2008) 5737], Diario Oficial, núm. L 307 de 18/11/2008 p. 0011-0014.

31 La igualdad de género se ha visto favorecida en virtud del nuevo programa, conocido como "Compromiso estratégico para la igualdad de género 2016-2019". Se trata de un programa que sigue los pasos previamente marcados por la Estrategia para la igualdad entre mujeres y hombres 2010-2015, de la Comisión.

32 Sin duda, el elevado número de jóvenes desempleados es un problema estructural en la Unión Europea. La Comisión propuso un paquete de empleo juvenil que comprendía una garantía juvenil europea (Recomendación del Consejo de 2013), una Alianza para la Formación de Aprendices y, finalmente, un marco de calidad para los periodos de prácticas (Recomendación del Consejo de 2014). 
contexto de escasos trabajos o de trabajos retribuidos a la baja, que limitan su integración social. Por último, debemos referirnos a las personas en situación de discapacidad ${ }^{33}$, que han contado igualmente con una línea específica de actuación ante sus particulares dificultades de integración social ${ }^{34}$.

\section{La reducción de la pobreza en el empleo desde la estrategia europea 2020}

La Estrategia Europea de 2020 es la base de apoyo del sistema de inclusión social y una firme respuesta orientada a contrarrestar las tasas de pobreza que últimamente han aumentado considerablemente. Con carácter general, conviene indicar que se ha producido un largo camino desde Lisboa a la Estrategia Europea 2020. La Estrategia de Lisboa de 2000 ya destacaba que la mejor salvaguarda contra la exclusión era el trabajo, insistiendo en la necesidad de bregar por el mantenimiento de un pacto social con pleno empleo y una protección universal. Se trataba de un fin esencial ante los peligros derivados del nuevo sistema económico que venía a desmontar el sistema social desde los años ochenta. Fue un gran logro derivado del año europeo de lucha contra la pobreza y la exclusión. La Estrategia de 2020 vino, pues, a sustituir a la fracasada Estrategia de Lisboa, previendo un objetivo más ambicioso en materia social. Asimismo, nace con un claro espíritu crítico, que viene a constatar el empeoramiento de las condiciones de exclusión social y pobreza en Europa (Estévez Araujo, 2019). Concretamente, se indica que existen más de ciento veinte millones de personas en la Unión Europea en riesgo de pobreza o exclusión social, asumiéndose el objetivo de rescatar, por lo menos, a veinte millones de personas en situación de exclusión. Por tanto, la lucha contra la pobreza y la exclusión social es el núcleo de la Estrategia Europa 2020.

Concretamente, uno de sus cinco objetivos es la reducción de pobreza en al menos veinte millones de personas, situación que afecta

33 Vid. "Discapacidad y exclusión social en la Unión Europea, tiempo de cambio, herramientas para el cambio". Informe HSO, Vammaisfoorumiry (Finnish Disability Forum) MHE-SME Inclusion Europe, Fundación Luis Vives, Comité Español de Representantes de Personas con Discapacidad-CERMI, julio 2003.

34 La Comisión Europea, en noviembre de 2010, adoptó una Estrategia Europea sobre Discapacidad 2010-2020 (COM, 2010, 636), sobre la base del plan de acción en materia de discapacidad 2004-2010. 
en concreto, en nuestros países, a casi un millón y medio de personas. Los objetivos de inclusión social se traducen en el acceso al empleo, la garantía de ingresos mínimos y servicios asequibles y adecuados, siendo ello el instrumento idóneo para luchar contra la pobreza y alcanzar nuevas cuotas de inclusión social. De igual modo, debemos recordar que la Estrategia 2020 acoge el mismo concepto de riesgo de pobreza y exclusión social previamente examinado, en el sentido de considerar no solamente la pobreza en términos económicos o nivel de renta, sino de marginación y exclusión social. Adopta, como criterios preferentes, la garantía del acceso al empleo, unida a la protección social y al acceso a los servicios esenciales. Todo ello se refuerza con el acceso, en condiciones de igualdad, a la sanidad y a los servicios sociales básicos, el apoyo especial a los jóvenes, la mejora de las condiciones de integración de los inmigrantes, las políticas de lucha contra la discriminación por razón de género y, entre otras, por la atención especial a los discapacitados.

La Estrategia Europea 2020 intenta reducir el número de ciudadanos europeos que viven por debajo del umbral de pobreza nacional en un $25 \%$. Esta cifra abstracta supone poder rescatar a más de veinte millones de personas de la situación de pobreza ${ }^{35}$. Se trata de un ambicioso objetivo que requiere inversión y cuyo dinamismo se ha visto reforzado con la Plataforma Europea contra la Pobreza y la Exclusión Social, creada ya en diciembre de $2010^{36}$. La Estrategia 2020 se concibe con un instrumento que permite dar respuesta a las nuevas directrices de la política laboral europea, que han venido fomentando la precariedad y la contención salarial. Estas propuestas de reforma de los mercados de trabajo estaban orientadas a la salida de la crisis y la mejora de la competitividad de la Unión Europea en el escenario mundial. Sin embargo, ello ha creado profundos problemas sociales, entre ellos, la atracción de la categoría de los trabajadores pobres como manifestación propia de otros mercados de trabajo.

35 Según la Estrategia Europea, en la Unión Europea se estima que hay más de ochenta millones de personas en situación de riesgo de pobreza, siendo el objetivo rebajar esta cifra en unos veinte millones de personas para el año 2020.

36 Vid. Plataforma Europea contra la Pobreza y la Exclusión Social: Un marco europeo para la cohesión social y territorial. SEC (2010) 1564 final COM (2010) 758 final, Bruselas, 16.12.2010. 
La Estrategia Europea sigue dejando, como ocurría en Lisboa, la acción contra la exclusión social y la pobreza a los Estados, los cuales deben diseñar políticas orientas a la lucha en favor de la inclusión social. En este modelo, la Comisión Europea ejerce funciones de coordinación, como sucede en materia de política social europea. De este modo, la Unión Europea tiene un importante límite legal al desarrollo de la estrategia contra la pobreza, ya que los propios tratados excluyen las políticas sociales del ámbito propio de la armonización de una política común. La exclusión social y la pobreza forman parte, pues, de la política social y, por tanto, su tratamiento queda extramuros del ámbito de decisión plena por parte de las instituciones europeas.

El modelo se inspira en una organización jerárquica de las competencias. El Consejo Europeo tiene plena potestad sobre la orientación de la Estrategia, realizando la Comisión funciones de coordinación, supervisión y control de la consecución de los objetivos; asimismo, estimula el intercambio político y promueve las iniciativas en el seno de la Unión Europea. Por su parte, el Parlamento Europeo realiza las labores de colegislador, junto a los parlamentos nacionales, y, finalmente, el aspecto competencial se completa con las labores propias de las autoridades nacionales y locales, que intervienen asegurando un espacio de acción a los agentes y organizaciones sociales. En definitiva, se trata de un modelo orientado a la plena participación de todos los entes comunitarios y nacionales, que deberán fomentar igualmente la participación de los ciudadanos ${ }^{37}$. Desde la Unión Europea se prevé la normativa básica y se facilita la financiación necesaria para aplicar las políticas de lucha contra la exclusión social. En esta política comunitaria destacan muy especialmente las medidas de inclusión social y, muy especialmente, la lucha contra la discriminación, que, como hemos analizado, cuenta con una importante regulación en la Unión Europea. El apartado institucional se complementa en nuestra materia con el desarrollo de la Plataforma Europea contra la Pobreza y la Exclu-

37 Ciertamente, la lucha contra la pobreza y la exclusión social es un asunto esencialmente de ámbito nacional. No obstante, la Unión Europea desempeña una importante labor de coordinación entre los distintos Estados, lo cual facilita la posibilidad de encontrar las mejores prácticas que pueden ser más efectivas en la práctica Hacia la inversión social para el crecimiento y la cohesión (2013). 
sión Social, cuya finalidad es garantizar la cohesión económica, social y territorial ${ }^{38}$.

La Estrategia Europa 2020 ha sido un plan de acción orientado al crecimiento de la Unión Europea para la década 2010-2020 y que actualmente se encuentra en fase de transición en el marco del desarrollo de la Agenda 2030. Dicho programa no contempla cualquier tipo de desarrollo económico y existe ciertamente una apuesta decidida por un modelo de crecimiento integrador. Es decir, el crecimiento económico debe favorecer la inclusión social ${ }^{39}$. Dicho crecimiento integrado consiste en intentar alcanzar una economía, social y territorialmente, favorable para todos los ciudadanos. En realidad, se trata un proceso de inversión social orientado a las personas, que proporcione más empleo y protección social, luchando contra la pobreza y avanzando hacia una sociedad más cohesionada. Sin duda, todo ello debe estar asentado en un reparto justo y equitativo de los beneficios derivados del crecimiento económico generado en la Unión Europea. Ello es esencial si se pretende reforzar la cohesión social y territorial, gracias a la garantía de la igualdad de oportunidades para todos los ciudadanos $^{40}$.

La Estrategia Europea de 2020 supone un gran paso en la lucha contra la exclusión social y la pobreza, pero el desafío sigue pendiente y queda mucho trabajo por hacer. Sin embargo, no está consiguiendo

38 Se trata, pues, de aumentar la conciencia y reconocer los derechos fundamentales de las personas que sufren la pobreza y la exclusión social, permitiéndoles vivir con dignidad y participar activamente en la sociedad. Vid. La Plataforma Europea contra la Pobreza y la Exclusión Social: Un marco europeo para la cohesión social y territorial (2010).

39 Esta idea se resalta especialmente en los siguientes informes oficiales. Vid. "La dimensión social de la estrategia Europa 2020. Un informe del comité de protección social", Oficina de Publicaciones de la Unión Europea, Luxemburgo 2011. "Towards Social Investment for Growth and Cohesion - including implementing the European Social", Fund 2014-2020, COM, 83 final, 2013, Brussels, 20.2.2013. Comisión Europea. "Europa 2020 - Una Estrategia para un crecimiento inteligente, sostenible e integrador". 2010. p. 42. Comisión Europea. "Europa 2020: la estrategia europea de crecimiento". 2013. p. 12.

40 Precisamente, la Estrategia Europea pone especial atención a factores como el empleo, atajando las altas tasas de desempleo actuales. Asimismo, dicho programa de acción tiende a contrarrestar la actual tendencia de la evolución demográfica de la población activa, que de forma progresiva experimenta una reducción acusada. Y, finalmente, se pretende luchar contra la pobreza para reducir el número de personas vulnerables a este riesgo. 
los objetivos de integración pretendidos. Ciertamente, son muchas las críticas que se han venido formulando a su aplicación $\mathrm{n}^{41}$. Se ha criticado la tendencia actual, que ha permitido tildar de "fracaso" el proceso de implementación, aunque se ha resaltado que esta política comunitaria ha permitido la mejora de la coordinación y cooperación entre los Estados y la Unión Europea. El objetivo pretendido para 2020 está aún lejano e, incluso, se ha visto agravado por el empeoramiento de las condiciones de vida, debido a la crisis económica. Todo ello en una situación de especial gravedad, que incluso ha venido a condicionar la propia sostenibilidad de los sistemas públicos de protección social. Asimismo, se ha considerado que se trata de un plan de acción continuista de la fallida Estrategia de Lisboa. Ciertamente, esta declaración contemplaba la mejora de la competitividad europea, prestando atención tanto a los aspectos económicos como sociales. Sin embargo, se daba más atención al crecimiento económico y al pleno empleo frente a los aspectos esencialmente sociales. En definitiva, este es el principal temor inherente al desarrollo de la Estrategia Europea, es decir, la cuestión es determinar si los fines económicos van a prevalecer sobre los derechos sociales. Sin duda, ello puede derivar en que la Estrategia 2020 se reoriente negativamente, siguiendo la tendencia de su predecesora.

Asimismo, esta situación la fomenta la propia Estrategia que, de forma ambigua, se refiere a la lucha contra la pobreza con referencias difusas a la inversión en capital humano y al fomento de un Estado de bienestar activo y dinámico, con el fin de alcanzar "una nueva economía del conocimiento". En cierto modo, parece que lo importante no es tanto erradicar la pobreza, sino no aumentar las diferencias sociales existentes, que derivan del desempleo y la exclusión social. Se ha visto claramente una gran diferencia entre los ambiciosos objetivos comunitarios y los programas de desarrollo por parte de los Estados. Ciertamente, existía un distanciamiento, en parte debido a la falta de entendimiento y a la presencia de recursos económicos limitados. Sin duda, la Estrategia requiere de un nuevo debate europeo, que afronte

41 En este sentido, se ha reiterado la línea continuista respecto de la Estrategia de Lisboa y la acusada parálisis del modelo, que tiene como base la propia crisis institucional europea (Sian, 2010; Subirats et al., 2001; Yang, 2010). Vid. Hacia la inversión social para el crecimiento y la cohesión (2013). 
decididamente los factores estructurales que están transformando las sociedades europeas y, con ello, el modelo social comunitario. Se debe prestar especial atención al problema del aumento de la pobreza laboral, así como a la distribución no equitativa de la riqueza.

\section{La importancia de la financiación de las políticas de contención de la pobreza}

Como hemos señalado, el factor clave del sistema de lucha contra la pobreza y la exclusión social es la financiación económica. El Fondo Social Europeo dota las partidas comunitarias, que permiten cofinanciar las acciones orientadas a la lucha contra la discriminación. Así, se permite compensar, mediante ayudas, la situación de las personas más desfavorecidas. Entre ellas destacan muy especialmente las acciones orientadas al empleo. En este sentido, podemos destacar la Iniciativa de Empleo Juvenil, financiada por el Fondo Social Europeo gracias a una línea especial del presupuesto comunitario. Ciertamente, el ambicioso objetivo de la lucha contra la exclusión social y la pobreza requiere de importantes inversiones que generen empleo e inclusión social. El Fondo Social Europeo permite que los Estados miembros determinen de qué manera van a emplearse los recursos económicos comunitarios para alcanzar los objetivos de la Estrategia $2020^{42}$.

Evidentemente, el éxito de la Estrategia Europa 2020 depende del diseño y coordinación de la política social y de su correcta financiación. Ello significa que la ayuda financiera de la Unión Europea deberá ir orientada a las prioridades de la Estrategia. Concretamente,

42 La Comisión Europea suscribe, con los Estados miembros, unos compromisos relativos al uso de los fondos a nivel nacional y regional, que deberán orientarse a la consecución de la Estrategia. Se prevén, pues, objetivos concretos, determinando condiciones relacionadas con la obtención de los resultados. Dicha financiación se evalúa cada año en virtud de los informes de política de cohesión. Asimismo, la financiación se reparte en atención a las necesidades de las regiones, orientando cómo deben emplearse dichos fondos. Así, se prioriza que los fondos tengan una importante finalidad de cohesión, atendiendo especialmente a aquellas regiones más pobres. 
el programa financiero 2014-2020 está orientado a este objetivo ${ }^{43}$. En este sentido, es posible que otras políticas hayan podido contribuir a contener o reducir los factores de pobreza y exclusión social. En su momento, se estimó que en torno al $3 \%$ del presupuesto comunitario se venía dedicando directamente a las políticas de integración social, manteniéndose en el tiempo este esfuerzo presupuestario ${ }^{44}$. Por tanto, el Fondo Social Europeo permite el desarrollo de acciones y medidas orientadas a la inclusión social de las personas en riesgos de exclusión, pero no hay que olvidar que, igualmente, se tiene en cuenta la atención de aquellas iniciativas que además resulten rentables económicamente. Este es un factor clave de la financiación, que se orienta a un concepto de inversión social rentable, que genere un retorno efectivo desde el punto de vista económico.

\section{Conclusiones}

Con el paso del tiempo, el sistema de protección contra la pobreza en la Unión Europea necesita una profunda revisión. Ante un contexto de reformas, es importante tener en cuenta los importantes logros conseguidos en la materia. El análisis retrospectivo nos debe de reafirmar en la necesidad de mantener los mecanismos que combaten la pobreza y garantizan la inclusión social, especialmente ahora en un contexto de crisis económica y social provocada por la pandemia. Se trata de una crisis que afecta al conjunto de los países europeos y que está replanteando las propias bases del sistema de protección social.

43 El Fondo Social Europeo da apoyo a las acciones de los países de la Unión que se orientan a la inclusión social de las personas más desfavorecidas. El presupuesto asignado para el periodo 2014-2020 asciende a 3.800 millones de euros. Se considera que dicha dotación económica representa más de un $15 \%$ adicional en la financiación nacional de los Estados miembros con arreglo a sus programas nacionales. En esta materia, es preciso destacar la proyección del Reglamento del Parlamento y el Consejo, Reglamento (UE) núm. 223/2014, relativo al Fondo de Ayuda Europea para las personas más desfavorecidas.

44 Vid. Un presupuesto para Europa 2020 (2011). SIN REFERENCIA. Se estima que, durante el periodo 2007-2013, el Fondo Social Europeo destinó unos diez mil millones de euros a la financiación de proyectos orientados a la lucha contra la exclusión social y el FEDER unos dieciocho mil millones de euros. En el caso de España puede consultarse el siguiente informe. Vid. Ministerio de Sanidad, Servicios Sociales e Igualdad, "La promoción de la inclusión social a través de los fondos estructurales y de inversión de la Unión Europea (período 2014-2020)", Madrid, 2014, pp. 24-ss. 
Actualmente, las instituciones europeas han reafirmado la necesidad de defender el pilar europeo de derechos sociales, en el que, sin duda, tiene un especial protagonismo la protección contra la pobreza y la mejora de la cohesión social. Este contexto demanda el desarrollo de nuevas políticas sociales y de protección del empleo. Igualmente, supone reforzar la propia acción de la Unión Europea con el objetivo de mejorar las condiciones de vida de los ciudadanos europeos, especialmente ante los efectos devastadores que está teniendo la actual crisis generada por el covid-19.

Ciertamente, las nuevas políticas promovidas por la Comisión Europea tienen que sustituir a la estrategia europea 2020. En esta transición se debe seguir considerando la lucha contra la pobreza, como eje de gravedad del modelo de protección social. Este nuevo esfuerzo de la Unión Europea debe igualmente seguir la senda de la Agenda 2030 de Naciones Unidas para el desarrollo sostenible, asimilando el objetivo de la lucha contra la pobreza como un pilar social de la acción institucional. En cualquier caso, no cabe duda de que dicho objetivo debe asentarse en los logros previamente conseguidos en materia de protección social, que se describen en el presente trabajo.

La noción de "pobreza" debe complementarse con la idea de "exclusión social", que permite avanzar en un concepto más amplio de protección ante las desigualdades entre los ciudadanos. Efectivamente, este proceso ha supuesto incluso una sustitución de la noción de la "pobreza", cobrando mayor relieve y sentido la referencia a la exclusión social. Dicho matiz se ha incorporado igualmente, como veremos, en la propia acción de la Unión Europea. Ello es importante porque permite evaluar el acceso y disfrute a los derechos sociales básicos, y el grado de promoción de la igualdad y no discriminación.

Nos encontramos ante una situación estructural. La pobreza en Europa no remite, ni siquiera en Europa occidental. Incluso, esta situación se potencia en los ciclos de crisis económica, que atraen nuevos problemas a los mercados de trabajos nacionales. Actualmente, debido a la crisis económica, se han producido profundos cambios en las estructuras económicas, políticas y sociales de los países. Ante esta situación, la Unión Europea debe buscar un nuevo modelo para mantener el núcleo social de protección, sin que ello suponga una pérdida de competitividad en el ámbito internacional. La Unión Eu- 
ropea está encontrando nuevos retos, en un escenario mucho más complejo, presidido por la globalización económica y el dumping social. Esta circunstancia se une a otros factores, como son el envejecimiento de la población y su incidencia en la financiación de los sistemas públicos de protección social.

La lucha contra la pobreza supone combatir la exclusión social y la discriminación en la sociedad, y muy especialmente en el ámbito laboral. Ello supone que los Estados deben combatir la pobreza integrando y cohesionando a la sociedad, y permitiendo que los ciudadanos tengan las mismas oportunidades y recursos. Se trata de un tema centrado especialmente en el punto de vista de las políticas sociales comunitarias. La exclusión social tiene un importante asiento jurídico en la legislación europea antidiscriminación y forma parte de la propia política social europea. La cuestión social ha sido un pilar fundamental de la Unión Europea. Ya durante la propia Comunidad Europea se vino a definir la noción de "pobreza" como elemento clave para entender el significado de la exclusión social.

La exclusión social y la pobreza son dos problemas interrelacionados, cuyos efectos se pretenden reducir mediante la toma de medidas impulsadas por la Estrategia Europea 2020, y que actualmente se desarrolla en la Agenda 2030 en ámbito de la aplicación de los objetivos de desarrollo sostenibles. En este sentido, el Consejo ha venido elaborando una serie de objetivos, insistiendo en que la Unión Europea tiene, entre sus principales fines, la lucha contra la pobreza y la exclusión social.

\section{Bibliografía}

Arriola, J. (2014). La estrategia de la Unión Europea de lucha contra la pobreza. Documento de Trabajo. Madrid: Fundación FOESSA.

Arroyo Bovea, M. (2016). Exclusión social y pobreza en la Unión Europea. GeoGraphos, Grupo Interdisciplinario de Estudios Críticos y de América Latina (GIECRYAL) de la Universidad de Alicante, 7(85).

Comisión Europea (2010). Recomendación de la Comisión Europea sobre inclusión activa de las personas excluidas del mercado de trabajo, Bruselas, 03.10.2008, núm. C(2008) 5737 (2008/867/ $\mathrm{CE})$. 
Comisión Europea (2010). La Plataforma Europea contra la Pobreza y la Exclusión Social: Un marco europeo para la cohesión social y territorial, Bruselas, 16.12.2010, $\operatorname{COM(2010)~} 758$.

Comisión Europea (2011). Un presupuesto para Europa 2020, Parte I, Bruselas, 29.06.2011, COM (2011) 500.

Comisión Europea (2012). Informe sobre la ejecución, los resultados y la evaluación general del Año Europeo de la Lucha contra la Pobreza y la Exclusión Social, Bruselas, 15.03.2012, COM(2012) 107 final.

Comisión Europea (2012): Investing in a social Europe. Report on the second annual conference of the European Platform against Poverty and Social Exclusion. Bruselas, 5-7 diciembre 2012.

Comisión Europea (2013). Hacia la inversión social para el crecimiento y la cohesión, relativo al paquete sobre inversión social, Bruselas, 20.2.2013, COM (2013) 83.

Consejo Europeo (1975). Decisión del Consejo Europeo de 22 de julio de 1975, relativa al programa piloto de estudio y luch a contra la pobreza (75/458/EEC), Official Journal L 199, 30/07/1975, p. 0034-0035

Consejo Europeo (1984). Decisión del Consejo de 19 de diciembre de 1984, relativa a una acción comunitaria especifica de lucha contra la pobreza (85/8/CEE ), Official Journal L 002, 03/01/1985, p. 0024-0025.

Eapn (2020). El Estado de la Pobreza. España 2020 X Informe anual sobre el riesgo de pobreza y exclusión, realizado por EAPN España. Evolución del indicador AROPE (At-Risk-Of Poverty and Exclusion).

Estévez Araujo, J. A. (2019). Pobreza y empleo en la estrategia Europa 2020. Oxímora: revista internacional de ética y política, (14).

Eurostat (2020). Europe 2020. A European strategy for smart, sustainable and inclusive growth, Bruselas, 03.03.2010, $\mathrm{COM(2010)}$ 2020.

Eurostat (1995). Statistics in Focus 1995/10

Fernández García, T. (2012). El Estado de Bienestar frente a la Crisis Política, Económica y Social. Portularia XII, 3(12).

Gil Villa, F. (2002). La exclusión social. Barcelona: Ariel.

Gil, J. (2009). Balance-Sheet of European Social Policy. Estudios de Economía Aplicada, (27), 3. 
Herrera Ballesteros, J. (2020). Pobreza laboral y desempleo en España 2009-2019. Trabajo: Revista Iberoamericana de Relaciones Laborales, (38).

Lacuesta, A. y Brindusa, A. (2020). La población en riesgo de pobreza o exclusión social en España, según la definición del Consejo Europeo. Boletín Económico del Banco de España, (1).

Lois González, R. C, Feal Pérez, A. y Paül i Carril, V. (2013). La dimensión territorial de la Estrategia Europa 2020. Las regiones europeas en la senda oficial para salir de la crisis. Ería: Revista cuatrimestral de geografía, (92), 211-242.

Ministerio de Sanidad, Consumo y Bienestar Social de España (2020). Estrategia nacional de prevención y lucha contra la pobreza y la exclusión social 2019-2023, Consejo de Ministros, Madrid.

Podadera, P., Romero, A., García, A. y Lobato, J. (2020). Pobreza y exclusión social en la Unión Europea. Revista de Economía Mundial, (55).

Quesada Díez, S. (1998). La acción social en la Unión Europea: evolución histórica. Alternativas. Cuadernos de Trabajo Social, (6).

Quesada Díez, S. (1998). La Acción Social en la Unión Europea: Evolución Histórica. Alternativas. Cuadernos de Trabajo Social, (6).

Rojas Mullor, M. (2011). Pobreza y exclusión social. La experiencia de la Unión Europea: conceptos y herramientas de acción. Cuadernos de la EPIC, (2).

Room, G. (1995). Poverty and social exclusion: the new European agenda for policy and research. In G. Room (ed.), Beyond the Threshold. The measurement and Analysis of Social Exclusion. UK Bristol: The Policy Press.

Sian, J. (2010). “La estrategia Europa 2020. ¿Influirá en la pobreza?", Revista de la Red Europea de Lucha contra la Pobreza y la Exclusión, EAPN, Vol. 133.

Subirats, J. et. Al. (2001). "Pobreza y exclusión social: Un análisis de la realidad española y europea”, Colección Estudios Sociales, Vol. 16, La Caixa.

Yang, W. (2010). Afrontando las complejidades de la pobreza", Departamento de Asuntos Económicos y Sociales, ONU. 